\title{
Persistent CT nephrograms following cardiac catheterisation and intervention: initial observations
}

\author{
Richard W. Katzberg • Wayne L. Monsky • Nicolas D. Prionas • Vishal Sidhar • \\ Jeffrey Southard $\cdot$ Janine Carlson $\cdot$ John M. Boone $\cdot$ Tzu-Chun Lin $\cdot$ Chin-Shang Li
}

Received: 18 July 2011 /Revised: 13 September 2011 / Accepted: 23 September 2011 /Published online: 16 November 2011

(C) European Society of Radiology 2011

\begin{abstract}
Objectives To describe persistent nephrographic patterns detected by unenhanced renal $\mathrm{CT}$ at $24 \mathrm{~h}$ after cardiac catheterisation and intervention.

Methods This prospective study was Health Insurance Portability and Accountability Act-compliant and institutional review board approved. Twenty-nine patients (20 men, nine women; average age 63.27 and range 4185 years) agreed to undergo unenhanced dual-energy computed tomography (CT) limited to their kidneys at 24 $\mathrm{h}$ after cardiac catheterisation. CT attenuation values (Hounsfield units) were made from the cortical and medullary regions and single kidney total parenchymal
\end{abstract}

Electronic supplementary material The online version of this article (doi:10.1007/s13244-011-0131-2) contains supplementary material, which is available to authorized users.

R. W. Katzberg $(\bowtie) \cdot$ W. L. Monsky $\cdot$ N. D. Prionas $\cdot$ V. Sidhar $•$

J. M. Boone

Department of Radiology,

University of California School of Medicine,

4860 Y Street, Suite 3100,

Sacramento, CA 95817, USA

e-mail: Richard.katzberg@ucdmc.ucdavis.edu

J. Southard $\cdot$ J. Carlson

Department of Cardiology,

University of California School of Medicine,

4860 Y Street, Suite 3100,

Sacramento, CA 95817, USA

T.-C. Lin · C.-S. Li

Division of Biostatistics,

University of California School of Medicine,

4860 Y Street, Suite 3100,

Sacramento, CA 95817, USA iodine values (milligrams) were measured. Spearman's rank correlation coefficient and a two-sided Fisher's exact test were used in the statistics.

Results Focal nephrograms were observed in at least one kidney (range, one to five regions per kidney) in 10/29 (34\%) of patients and bilateral global nephrograms in 13/29 (45\%) of patients. Focal nephrograms correlated with cardiac catheterisation fluoroscopic time $(r=0.48 ; P=$ 0.0087). For global nephrograms, the total iodine content of right and left kidneys correlated with fluoroscopic time ( $r=0.79$ and $0.76 ; P<0.0001$, respectively) and the amount of contrast material $(\mathrm{CM})$ used $(r=0.77$ and $r=0.74 ; P<$ 0.0001 , respectively).

Conclusion Persistent focal and global nephrograms occur commonly as assessed by non-contrast CT at $24 \mathrm{~h}$ post cardiac catheterisation and our observations suggest they could be related to procedural factors.

Keywords Cardiac $\cdot$ Interventional $\cdot$ Urogenital Contrast media $\cdot \mathrm{CT}$

\section{Introduction}

Recent clinical commentaries suggest that acute kidney injury (AKI) is more likely to occur following cardiac catheterisation and intervention than with contrastenhanced computed tomography (CECT), especially in renally compromised patients $[1,2]$. Some have questioned whether the differential rates of AKI are the result of contrast-induced nephropathy (CIN) or factors related to the cardiac catheterisation procedure itself, and/or the greater degrees of pre-existing comorbidities found in patients with 
cardiac disease [1-5]. Post cardiac catheterisation cerebral emboli have been described in up to $15 \%$ of patients detected by transcranial Doppler and diffusion-weighted magnetic resonance imaging (MRI) [6, 7] and myocardial microinfarcts in $28 \%$ detected by MR [8-10]. We are not aware of any imaging studies that have assessed possible analogous renal complications, although they would seemingly be likely to occur.

Focal, segmental nephrograms on delayed CT scans have been uncommonly reported, but are believed to be a possible indication of AKI, related to focal renal ischemia. Yamazaki et al. [11] and Monsky et al. [12] observed segmental, wedge-shaped nephrograms, as well as global nephrograms on delayed CT scans following transarterial chemoembolisation (TACE), with the global nephrograms being associated with AKI. Monsky et al. [12] postulated that the delayed CT segmental nephrograms could represent foci of renal injury secondary to renal emboli related to the catheterisation procedure itself.

Other studies have suggested that a persistent nephrogram is an indicator of significant AKI. Older et al. [13] and Love et al. [14] reported that persistent, bilateral and global nephrograms detected by either plain radiography or delayed $\mathrm{CT}$ are indicative of acute renal failure (ARF) related to $\mathrm{CIN}$.

The meaning remains unclear whether there is a correlation with the incidence of CIN or cardiac catheterisation. We describe the 24-h delayed nephrographic CT findings and compare these with procedure time, amount of contrast material $(\mathrm{CM})$ administered and changes in the serum creatinine $(\mathrm{SCr})$.

\section{Materials and methods}

\section{Patient selection}

This prospective Health Insurance Portability and Accountability Act-compliant study was approved by our institutional review board. Between June 2010 and January 2011, 124 patients were approached at random to participate in the study prior to their cardiac catheterisation procedure at our institution. Patients were asked if they would be willing to undergo a limited dual energy CT scan of their kidneys $24 \mathrm{~h}$ after their cardiac catheterisation procedure to assess the possible persistence of $\mathrm{CM}$ (nephrogram) in their kidneys. Patient selection was also based on their willingness to acquire a $\mathrm{SCr}$ at $48-72 \mathrm{~h}$ post procedure. Exclusion criteria were subjects younger than 18 years old, an estimated glomerular filtration rate (eGFR; Modified Diet in Renal Disease estimation) [15] $<60 \mathrm{ml} / \mathrm{min}$, having undergone or being scheduled to undergo any other radiographic procedures requiring iodinated contrast media from $72 \mathrm{~h}$ before to $72 \mathrm{~h}$ after the cardiac catheterisation procedure, having a hypersensitivity to iodine-containing contrast media requiring prophylactic medication, or being pregnant or lactating females. Eighty-nine patients were initially excluded for the following reasons: 72 declined the consent or were unable to comply with follow-up 48-72 h SCr; ten had an eGFR $<60 \mathrm{ml} / \mathrm{min}$; four had another scheduled contrast medium study; two had a history of contrast medium hypersensitivity requiring prophylactic premedication. From the resulting patients, 35 were enrolled following signed informed consent for the 24-h delayed CT examination. Three patients did not appear for CT, the CT system was not available in one case, one patient withdrew consent and one patient had a change in treatment after enrollment. Thus, 29 patients completed the 24-h CT protocol (Table 1). An increase in $\mathrm{SCr}$ from baseline values of $\geq 44 \mu \mathrm{mol} / 1(0.5 \mathrm{mg} / \mathrm{dl})$ or $\geq 25 \%$ were recorded as changes in renal function significant enough to be classified as CIN as defined by the European Society of Urogenital Radiology [16].

\section{Cardiac catheterisation procedures}

Patients were selected for cardiac catheterisation based on clinical signs and symptoms of chest pain consistent with angina. All patients had baseline blood tests to include a complete blood count (CBC), chemistry panel and prothrombin time-international normalised ratio (PT-INR) before angiography. Included in the preliminary clinical assessment were baseline serum creatinine and blood urea nitrogen (BUN).

Informed consent for the cardiac catheterisation procedure was acquired following the discussion of risks, benefits, complications and alternatives to the procedure. The patients were brought to the catheterisation laboratory in a fasting state. In patients with an eGFR $\geq 60 \mathrm{ml} / \mathrm{min}$, there is no routine pre-medication or hydration protocol used. Intravenous fentanyl, midazolam and inapsine were used for sedation. Lidocaine $1 \%$ without epinephrine was used for local anesthesia. Visipaque (Iodixanol, 320 $\mathrm{mgI} / \mathrm{ml}$; osmolality $290 \mathrm{mOsm} / \mathrm{kg}$ and viscosity $11.8 \mathrm{cps}$ at $37^{\circ} \mathrm{C}$; GE Healthcare, Princeton, New Jersey) was the contrast medium in all cases. Arterial access from either the femoral artery or the radial artery was obtained using a modified Seldinger technique, with or without ultrasound guidance.

At the completion of the procedure, the total $\mathrm{CM}$ utilised and the total amount of fluoroscopy time was recorded and documented. Patients had their catheter sheaths discontinued when their activated partial thromboplastin time (aPTT) was less than $50 \mathrm{~s}$ or their ACT was less than $180 \mathrm{~s}$ and remained in the supine position for variable amounts of time, depending on whether or not a closure device was placed. Radial 
Table 1 Clinical parameters

\begin{tabular}{|c|c|c|c|c|c|c|c|c|c|}
\hline \multirow[b]{2}{*}{$\begin{array}{l}\text { Patient } \\
\text { number }\end{array}$} & \multirow[b]{2}{*}{ Age } & \multirow[b]{2}{*}{ Gender } & \multirow[b]{2}{*}{ Intervention } & \multirow[b]{2}{*}{$\begin{array}{l}\text { Total contrast } \\
\text { (ml Visipaque) }\end{array}$} & \multirow[b]{2}{*}{$\begin{array}{l}\text { Total fluoro } \\
\text { time }^{\mathrm{a}}\end{array}$} & \multirow[b]{2}{*}{$\begin{array}{l}\text { Baseline eGFR } \\
\left(\mathrm{ml} / \mathrm{min} / 1.73 \mathrm{~m}^{2}\right)\end{array}$} & \multicolumn{3}{|l|}{$\mathrm{SCr}$ data $^{\mathrm{c}}$} \\
\hline & & & & & & & Baseline & $24 \mathrm{~h}$ & $48-72 \mathrm{~h}$ \\
\hline 1 & 65 & M & Angioplasty and stent & 240 & 17.00 & 80 & $83.60(0.95)$ & $101.20(1.15)$ & $86.24(0.98)$ \\
\hline 2 & 66 & M & Angioplasty and stent & 300 & 15.40 & 74 & $88.88(1.01)$ & $88.00(1.00)$ & - \\
\hline 3 & 58 & M & None & 150 & 10.10 & 105 & $66.88(0.76)$ & - & $66.00(0.75)$ \\
\hline 4 & 64 & M & Balloon angioplasty $\times 2$ & 270 & 21.10 & 67 & $96.8(1.10)$ & $97.68(1.11)$ & $121.44(1.38)$ \\
\hline 5 & 69 & $\mathrm{~F}$ & None & 100 & 6.15 & 65 & $76.56(0.87)$ & - & $93.28(1.06)$ \\
\hline 6 & 56 & $\mathrm{~F}$ & None & 100 & 7.00 & 80 & $66.00(0.75)$ & - & $84.48(0.96)$ \\
\hline 7 & 56 & $\mathrm{~F}$ & Stent & 300 & 20.50 & 96 & $56.32(0.64)$ & - & $60.72(0.69)$ \\
\hline 8 & 51 & $\mathrm{~F}$ & None & 150 & 14.60 & 85 & $63.36(0.72)$ & $60.72(0.69)$ & - \\
\hline 9 & 73 & M & $\begin{array}{l}\text { None-3 vessel } \\
\text { disease, referred for } \\
\text { CABG }\end{array}$ & 180 & 12.30 & 104 & $65.12(0.74)$ & - & $73.92(0.84)$ \\
\hline 10 & 71 & M & None & 120 & 3.60 & 82 & $80.08(0.91)$ & - & $90.64(0.99)$ \\
\hline 11 & 71 & M & None & 130 & 12.10 & 76 & $85.36(0.97)$ & $88.00(1.00)$ & $90.64(1.03)$ \\
\hline 12 & 68 & M & $\begin{array}{l}\text { Rotational atherectomy } \\
\text { with stent }\end{array}$ & 370 & 32.30 & 68 & $95.04(1.08)$ & - & $95.92(1.09)$ \\
\hline 13 & 60 & M & None & 80 & 9.50 & 84 & $80.96(0.92)$ & - & - \\
\hline 14 & 69 & M & $\begin{array}{l}3 \text { stents with rotational } \\
\text { atherectomy }\end{array}$ & 460 & 58.60 & 79 & $83.60(0.95)$ & $80.96(0.92)$ & $96.80(1.10)$ \\
\hline 15 & 68 & M & 3 stents & 325 & 25.30 & 68 & $95.04(1.08)$ & $80.08(0.91)$ & $79.20(0.90)$ \\
\hline 16 & 71 & M & None & 145 & 10.20 & 67 & $95.04(1.08)$ & $81.84(0.93)$ & $220.88(2.51)$ \\
\hline 17 & 41 & $\mathrm{~F}$ & None & 130 & 9.60 & 63 & $85.36(0.97)$ & - & $101.2(1.15)$ \\
\hline 18 & 51 & M & 3 stents & 380 & 33.10 & 154 & $49.28(0.56)$ & $63.36(0.72)$ & $65.12(0.74)$ \\
\hline 19 & 57 & M & Stent & 280 & 32.30 & 70 & $95.92(1.09)$ & - & $107.36(1.22)$ \\
\hline 20 & 66 & M & None & 150 & 13.70 & 88 & $76.56(0.87)$ & $69.52(0.79)$ & $75.68(0.86)$ \\
\hline 21 & 61 & M & Stent & 180 & 15.30 & 92 & $74.80(0.85)$ & $72.16(0.82)$ & $88.88(1.01)$ \\
\hline 22 & 65 & $\mathrm{~F}$ & $\begin{array}{l}3 \text { vessel disease, } \\
\text { referred for CABG }\end{array}$ & 20 & 21.00 & 73 & $69.52(0.79)$ & $43.12(0.49)$ & $66.00(0.75)$ \\
\hline 23 & 85 & $\mathrm{~F}$ & Stent & 240 & 17.30 & 68 & $70.470(0.80)$ & $59.84(0.68)$ & $63.36(0.72)$ \\
\hline 24 & 56 & M & None & 77 & 12.30 & 93 & $74.80(0.85)$ & $74.80(0.85)$ & $89.76(1.02)$ \\
\hline 25 & 52 & $\mathrm{~F}$ & 3 stents & 175 & 29.50 & 60 & $86.24(0.98)$ & - & $87.12(0.99)$ \\
\hline 26 & 65 & $\mathrm{~F}$ & None & 90 & 5.60 & 63 & $79.20(0.90)$ & - & $82.72(0.94)$ \\
\hline 27 & 73 & M & None & 65 & 8.40 & 61 & $103.84(1.18)$ & - & $113.52(1.29)$ \\
\hline 28 & 67 & M & 3 stents & 340 & 35.20 & 63 & $101.20(1.15)$ & - & $95.92(1.09)$ \\
\hline 29 & 60 & M & $\begin{array}{l}\text { Rotational atherectomy } \\
\text { stents } \times 2 \text {, and balloon } \\
\text { angioplasty }\end{array}$ & 475 & 49.00 & 87 & $78.32(0.89)$ & $62.48(0.71)$ & - \\
\hline
\end{tabular}

${ }^{a}$ Fluoroscopy time in minutes

${ }^{\mathrm{b}} e G F R$ estimated glomerular filtration rate (MDRD equation)

${ }^{\mathrm{c}} \mathrm{SCr}$ serum creatinine $\mu \mathrm{mol} / \mathrm{l}(\mathrm{mg} / \mathrm{dl})$

artery access patients had their sheaths removed in the laboratory before returning to the ward. Outpatients having only a diagnostic cardiac catheterisation procedure were sent home on the same day after adequate hemostasis had been obtained at the arterial puncture site. Patients undergoing coronary intervention remained hospitalised overnight for observation as per standard protocol.
CT image acquisition

All CT images were obtained using dual energy CT (DECT) (Somatom-Definition DS, software version VE20: Siemens Healthcare) operated in the dual-energy mode with tube $\mathrm{A}$ at $80 \mathrm{kV}$ and $499 \mathrm{~mA}$, tube $\mathrm{B}$ at $140 \mathrm{kV}$ and $118 \mathrm{~mA}$ (effective milliampere seconds of 714 and 168, respectively), and a collimation of $14 \times 1.2 \mathrm{~mm}$. Two image sets with 5.0- 
mm-thick and 1.5 -mm-thick sections were reconstructed by using H30 (medium smooth) and D37s (dual-energy, medium sharp) kernels, respectively. Each image set consisted of an $80-\mathrm{kV}$ series, a $140-\mathrm{kV}$ series, and a third series, which combined the $80-\mathrm{kV}$ and $140-\mathrm{kV}$ images to produce a virtual $120-\mathrm{kV}$ image set. The combined images have a higher signal-to-noise ratio than the constituent $80-\mathrm{kV}$ and 140-kV image sets.

\section{Image interpretation}

The DECT nephrographic images were independently assessed by three operators. One operator was a radiology resident; one, an interventional radiologist with 20 years of clinical experience; and the third was a genitourinary radiologist with 35 years of clinical experience. Each observer was provided with two nephrographic imaging sets. The first imaging set depicted a grading scale for the global nephrograms, as demonstrated on the combined imaging series (Fig. 1a-d). This included kidneys without a nephrogram, kidneys with a minimally bilaterally dense nephrogram, kidneys with a moderately bilaterally dense nephrogram, and kidneys with a markedly dense bilateral nephrographic pattern. The second imaging set included images of a focal nephrogram (Fig. 2a, b). The observers were also asked to identify whether vicarious excretion of $\mathrm{CM}$ was identifiable either by gallbladder opacification or gallbladder and/or gut opacification (Figs. 1b, d and 5a, b). Intraluminal bowel or gallbladder, visually dense material was considered a positive finding. After the readers completed their review of the 29 unenhanced CT studies at $24 \mathrm{~h}$ after cardiac catheterisation, they met as a group and finalised the scores by consensus.

Quantitative CT image assessment at $24 \mathrm{~h}$ post cardiac catheterisation

\section{Cortical and medullary attenuation}

Circular regions of interest (ROIs) for the attenuation values in HU of the cortical and medullary regions of each kidney ( 29 subjects and 57 kidneys) were acquired by one of the investigators having 20 years of clinical radiology experience from the $120-\mathrm{kV}, 5-\mathrm{mm}$ slice thickness CT renal images. The circular ROI, measuring $5 \mathrm{~mm}$ in diameter, was applied to similar areas of the posterior upper pole, mid and lower pole for each kidney. The average HU values


Fig. 1 CT images providing a grading scale for intensity of delayed nephrograms from none to marked. Three ROIs (range $0.2-0.5 \mathrm{~cm}^{2}$ ) of anterior, lateral and posterior cortex and the median attenuation values (HU) of right and left kidneys are presented. a Axial CT of kidneys in a non-contrast study performed for liver imaging. Abdomen window width and level show the cortical median values $35.2 \mathrm{HU}$ and $34.3 \mathrm{HU}$, right and left kidneys, respectively. b CT nephrograms classified as faint with cortical median values $64.9 \mathrm{HU}$

and $61.8 \mathrm{HU}$, right and left kidneys, respectively. There is faint vicarious excretion in the ascending colon. Presumed densely calcified lumph node in the mid abdomen was present on prior CT scans. c CT nephrograms classified as moderate with cortical median values 91.8 HU and 93.6 HU, right and left, respectively. d CT nephrograms classified as marked with cortical median values $156.4 \mathrm{HU}$ and 163.3 $\mathrm{HU}$, right and left kidneys, respectively. Vicarious excretion is noted in the descending colon and small bowel 
Fig. 2 Coronal (a) and axial (b) CT images showing a wedge-shaped, peripheral focal nephrogram (arrow)
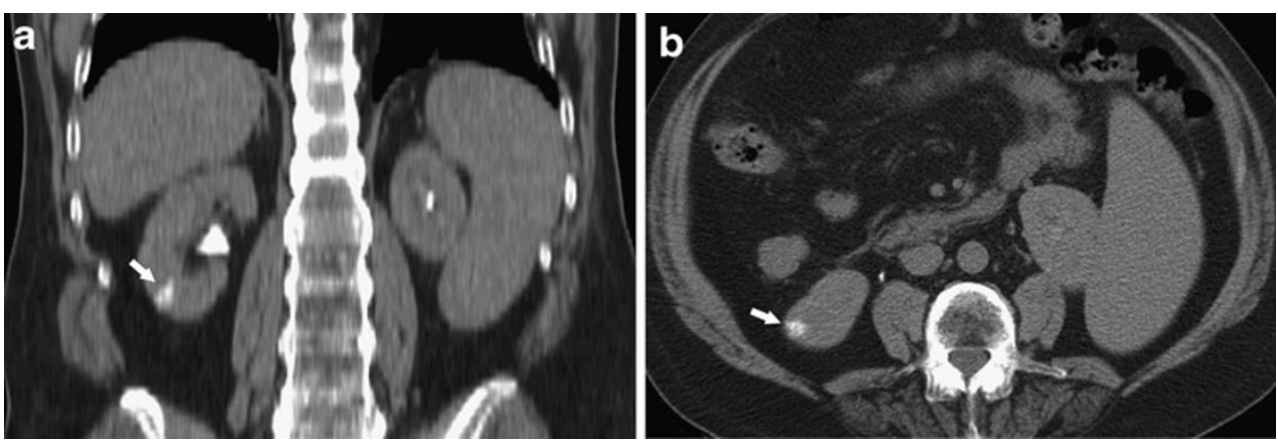

were recorded separately for the cortex and medulla of each kidney. Care was taken not to include adjacent tissues. These were acquired without knowledge of the semiqualitative assessment results or of any of the clinical parameters. The focal, segmented nephrograms were not measured quantitatively since they were often too small for accurate ROI placement.

\section{Single kidney total iodine content}

Total renal iodine content in each kidney was derived from the dual energy data using both subtraction and thresholding techniques. The thresholding technique was employed since, some of the dual energy data were inadvertently erased and some subjects were too large for the limited field of view for the $80 \mathrm{kV}$ image acquisition. Of the 29 patients recruited into the study, the complete image data set $(80 \mathrm{kV}, 140 \mathrm{kV}$, combined image, and subtraction image) was saved for 18 . Of the 18 complete data sets, 12 left kidneys (LKs) and 11 right kidneys (RKs) were in the field of view for dual energy subtraction. These were used as training sets to assess total iodine content of the 11 patients with erased data, as described in the "Electronic supplementary material".

\section{Statistical analysis}

Summary statistics are reported as the mean \pm standard deviation (median, minimum-maximum) for patient age, cortical and medullary attenuation values (Hounsfield units), total kidney iodine, baseline eGFR, amount of CM used and fluoroscopy time for the cardiac catheterisation procedure. Spearman's rank correlation coefficients were used to study the correlation in which we tested the null hypothesis that the correlation coefficient of zero versus the alternative hypothesis that the correlation is not equal to zero. The two-sided Fisher's exact test was used to compare any increase in $\mathrm{SCr}$ from baseline values with the occurrence of global nephrograms. A $P$ value $<0.05$ was considered statistically significant. All analyses were performed with SAS Version 9.2 (SAS Institute, Cary, $\mathrm{NC}, \mathrm{USA}$ ).

\section{Results}

The mean patient age was $63.27 \pm 8.8(65,41-85)$ years old and with a male-to-female ratio of 20:9 (Table 1). Intervention was performed in 16 subjects $(55 \%)$ and diagnostic only in 13 subjects (45\%), respectively. The femoral approach was used in 27 patients and the radial approach in two patients. The mean baseline eGFR was $79.8 \pm 19.1$ $(76,60-154) \mathrm{ml} / \mathrm{min}$. Four of 29 (14\%) of subjects (nos. 4, 6, 16 and 18; Table 1) showed one or both an increase in $\mathrm{SCr}$ of $\geq 44 \mu \mathrm{mol} / 1(0.5 \mathrm{mg} / \mathrm{dl})$ or $\geq 25 \%$. Two of these subjects showed a persistent nephrogram and two did not. All four subjects had hypertension; three had hyperlipidemia; one had diabetes Type 1; and one had diabetes Type 2. There were no patients deemed to have clinically significant AKI requiring extended hospitalisation, additional medication or dialysis. The mean CM used for the cardiac catheterisation procedure was $213.86 \pm 116.0$ (180, 65-475) $\mathrm{ml}$ and fluoroscopic time $19.2 \pm 13.1$ (15.3, 3.658.6) $\min$ (Table 1).

\section{CT image interpretation}

One or more focal nephrograms were observed in at least one kidney in 10/29 (34\%) patients and 15/57 (26\%) kidneys (Table 2; Figs. 3a-c and 4a, b). These ranged from one to five foci per kidney. Global nephrograms were bilateral in all patients and were observed in 13/29 (45\%) (Fig. 5a-c). Eight of 29 (27.5\%) were faint and 5/29 (17\%) were of moderate density. Vicarious CM excretion in gallbladder, gut or both was observed in 21/29 (72\%) of patients.

Quantitative CT assessment at $24 \mathrm{~h}$ post cardiac catheterisation

The mean right and left renal cortical mean attenuation values were $61.2 \pm 24.8(59,28.7-153) \mathrm{HU}$ and $60.1 \pm$ 23.1 (60.5, 32-135) HU, respectively (Table 2). The mean right and left medullary mean attenuation values were $42.2 \pm 12.9$ (41, 2-84) HU and 43.7 12.9 (42, 21.278) HU, respectively. The mean single kidney total iodine 
Table 2 Nephrogram parameters

\begin{tabular}{|c|c|c|c|c|c|c|c|c|c|}
\hline \multirow[b]{2}{*}{ Patient number } & \multicolumn{2}{|c|}{ Focal $^{\mathrm{a}}$} & \multirow{2}{*}{$\begin{array}{l}\text { Global }^{\mathrm{b}} \\
\text { (Both kidneys) }\end{array}$} & \multicolumn{4}{|c|}{ Cortical and medullary HUs } & \multicolumn{2}{|l|}{ 24-h total iodine } \\
\hline & $\mathrm{RK}$ & LK & & Rt cortex & Left cortex & Rt medulla & Left medulla & $\mathrm{RK}$ iodine total (mg) & $\mathrm{LK}$ iodine total $(\mathrm{mg})$ \\
\hline 1 & 1 & 0 & 0 & 59 & 61 & 43 & 31 & 269.44 & 247.68 \\
\hline 2 & 0 & 0 & + & 78.5 & 89.6 & 55 & 55.6 & 256.94 & 266.05 \\
\hline 3 & 0 & 1 & 0 & 52 & 34.6 & 32 & 41 & 269.9 & 324.69 \\
\hline 4 & 0 & 0 & + & 69 & 64 & 42.5 & 48 & 277.43 & 346.08 \\
\hline 5 & 0 & 0 & 0 & 59 & 56 & 43 & 57 & 109.02 & 117 \\
\hline 6 & 0 & $(-)$ & 0 & 43.1 & (no LK) & 46 & (no LK) & 228.61 & (no LK) \\
\hline 7 & 0 & 0 & ++ & 71.4 & 65.1 & 44.6 & 43.1 & 444.04 & 401.17 \\
\hline 8 & 0 & 1 & 0 & 48 & 33 & 32 & 33 & 207.66 & 208.96 \\
\hline 9 & 0 & 0 & + & 82 & 67 & 84 & 70 & 194.41 & 205.98 \\
\hline 10 & 0 & 0 & 0 & 36 & 32 & 23 & 22 & 141.12 & 146.05 \\
\hline 11 & 0 & 0 & 0 & 52 & 60 & 50 & 52 & 133.28 & 89.86 \\
\hline 12 & 2 & 2 & ++ & 81 & 91 & 41 & 44 & 518.67 & 458.74 \\
\hline 13 & 0 & 0 & 0 & 43.7 & 53.9 & 37.5 & 47.1 & 136.97 & 128.58 \\
\hline 14 & 1 & 1 & ++ & 153 & 135 & 70 & 56 & 387.87 & 364.42 \\
\hline 15 & 0 & 0 & + & 73 & 66.7 & 38 & 35 & 191.09 & 184.62 \\
\hline 16 & 0 & 0 & 0 & 28.7 & 48 & 46.1 & 43 & 152.15 & 135.66 \\
\hline 17 & 0 & 0 & 0 & 40 & 48 & 21 & 37 & 139.1 & 91.09 \\
\hline 18 & 0 & 0 & + & 75.8 & 73.2 & 37 & 39.8 & 264.52 & 254.07 \\
\hline 19 & 1 & 0 & 0 & 60 & 46 & 36 & 38 & 261.07 & 223.48 \\
\hline 20 & 0 & 0 & 0 & 43 & 33.8 & 31.2 & 21.2 & 208.93 & 209.56 \\
\hline 21 & 0 & 0 & 0 & 35.4 & 39.6 & 29.8 & 37.8 & 196.64 & 192 \\
\hline 22 & 2 & 2 & + & 76 & 68 & 41 & 39 & 491.18 & 538.82 \\
\hline 23 & 0 & 0 & ++ & 73 & 93 & 57 & 78 & 366.73 & 405.28 \\
\hline 24 & 1 & 0 & 0 & 36 & 32 & 34 & 28 & 185.25 & 183.61 \\
\hline 25 & 1 & 2 & + & 75 & 69 & 42 & 44 & 374.81 & 368.83 \\
\hline 26 & 0 & 0 & 0 & 39 & 47 & 46 & 41 & 127.12 & 117.95 \\
\hline 27 & 0 & 0 & 0 & 35 & 38 & 32 & 36 & 105.98 & 110.01 \\
\hline 28 & 5 & 5 & ++ & 80 & 72 & 40 & 60 & 654.74 & 655.83 \\
\hline 29 & 0 & 0 & + & 77 & 65 & 48 & 45 & 312.07 & 308.93 \\
\hline
\end{tabular}

${ }^{\mathrm{a}} 0$ none; $1,3 \ldots$ focal areas for each kidney

${ }^{\mathrm{b}} 0$ none; + faint; ++ moderate; +++ marked

content for the right and left kidneys was $262.3 \pm 135.6$ (228.6, 106-754.7) $\mathrm{mg}$ and $260.2 \pm 141.9$ (216.5, 89.9$655.8) \mathrm{mg}$, respectively. Iodine burden measured from combined image using global thresholds for LK and RK are shown in Table 2.

\section{Parameter correlation results}

There were good correlations (correlation coefficients $0.62-$ $0.7)$ between total single kidney iodine (milligrams) and cortical, but not medullary HUs (correlation coefficients $0.22-0.31$ ) with each kidney (Table 3). Cortical versus cortical and medullary versus medullary HUs between kidneys showed high correlations (correlation coefficients 0.86 and 0.75 , respectively). There was a statistically significant correlation $(r=0.48 ; P=0.0087)$ between the number of focal nephrograms in each patient and fluoroscopic procedure time, but not with total contrast used ( $r=$ $0.28 ; P=0.14$ ) (Table 4). The qualitative assessments of the global nephrograms showed good to high correlations with cortical and medullary HUs and single kidney total iodine (mg) values (range of correlation coefficients $0.47-0.87$ ) (Table 5).

The baseline eGFRs did not show relationships with either cortical or medullary HUs or single kidney total iodine content. The correlation coefficients ranged from -0.19 to 0.03 and $P$ values ranged from 0.34 to 0.86 . There was no statistically significant difference $(P=0.4097)$ in the increase of $\mathrm{SCr}$ from baseline in those subjects observed to have global nephrograms. 

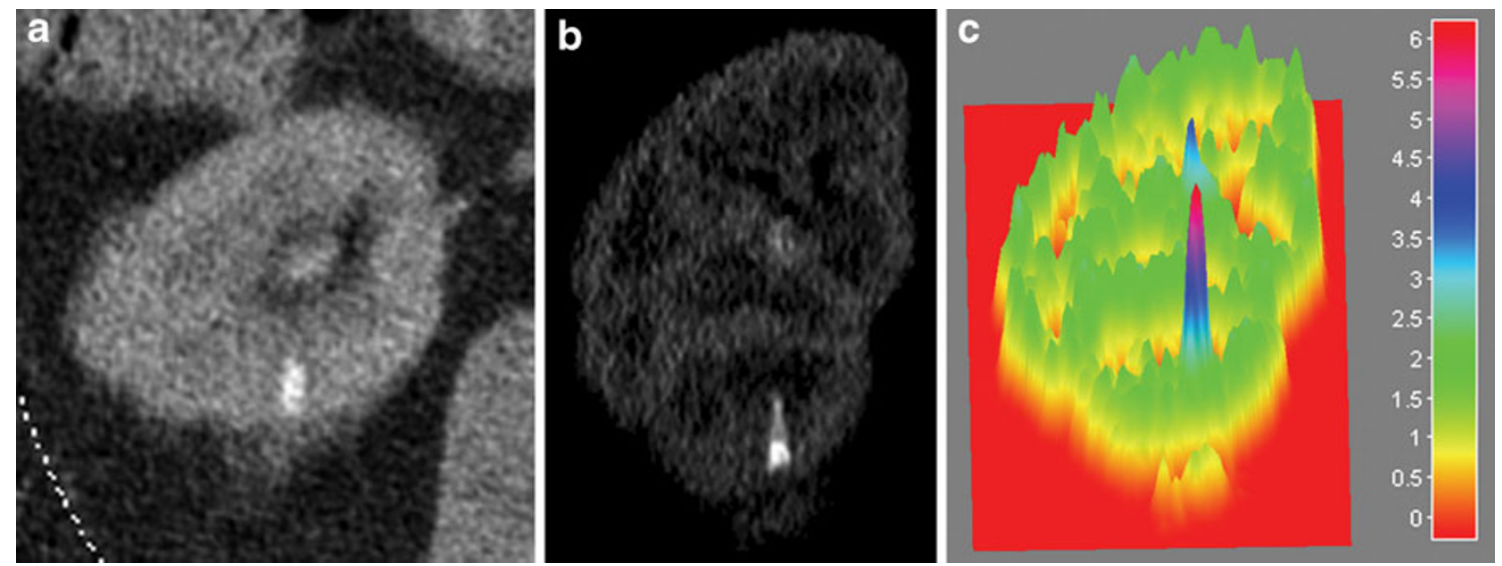

Fig. 3 Non-contrast CT images of a 68-year-old man (patient 12) 24 $\mathrm{h}$ after coronary rotational atherectomy and stent requiring a total of $370 \mathrm{ml} \mathrm{CM}$ and $32.3 \mathrm{~min}$ of fluoroscopy time. a Axial image of the right kidney shows a focal nephrogram in the posterior parenchyma superimposed on global nephrograms. b Coronal $80-\mathrm{kVp}$ image

There were strong correlations between both $\mathrm{CM}$ dose and fluoroscopy time with cortical HUs and single kidney iodine in milligrams, but not medullary HUs (Table 6).

\section{Discussion}

We report a frequent occurrence of persistent nephrograms detected by CT $24 \mathrm{~h}$ after cardiac catheterisation with or without intervention. Focal nephrograms were observed in 34\% (10/29) and bilateral global nephrograms in $45 \%(13 / 29)$ of patients. Positive correlations were found between fluoroscopic procedure time for focal nephrograms and both $\mathrm{CM}$ dose and fluoroscopic procedure time for the global nephrograms. There was no correlation between global nephrograms and baseline renal function defined by the eGFR. Increases in $\mathrm{SCr}$ at 24-72 $\mathrm{h}$ post cardiac catheterisation did not show a showing the same focal nephrogram in the lower pole posterior parenchyma. c Coronal two-dimensional (2D) colourised graphical image depicting both the global and focal nephrograms. The colourised scale on the right aspect of the image is in $\mathrm{mgI} / \mathrm{ml}$

relationship to the occurrence of global nephrograms. Four of 29 (14\%) of subjects experienced either one or both an increase in $\mathrm{SCr} \geq 44 \mu \mathrm{mol} / 1(0.5 \mathrm{mg} / \mathrm{dl})$ and $\geq 25 \%$. These are significant enough transient changes in kidney function to qualify for the criteria defined for CIN [16], although the numbers are too small to establish a direct link to the $\mathrm{CM}$, alone, versus other potential risk factors. No subjects required extended hospitalisation or additional medical management.

Segmental, wedge-shaped nephrograms on delayed imaging studies have been uncommonly reported. Anecdotal case reports were described by Ishikawa et al. [17] in 1985, by Pazimiño et al. [18] in 1983, by Braedel et al. [19] in 1987, and by Trueba-Arguinareña et al. [20] in 1977. Yamazaki et al. [21] reported focal residual contrast media in $16 \%(17 / 105)$ of patients by delayed CT at $24 \mathrm{~h}$ following abdominal angiography and found no association with CIN. The focal nephrograms were related to larger volumes of
Fig. 4 Non-contrast CT images of a 69-year-old man (patient 14) $24 \mathrm{~h}$ after atherectomy and $460 \mathrm{ml} \mathrm{CM}$ and $58.6 \mathrm{~min}$ of fluoroscopy time. a Wedgeshaped focal nephrogram in the coronal image of the left kidney at the $80-\mathrm{kVp}$ CT image. Arrows outline the margins of the peripheral, focal nephrogram superimposed on the increased global nephrogram. b Coronal 2D colourised graphical depiction of the iodine distribution as shown in Fig. 1c. The colourised scale on the right aspect of the image is in $\mathrm{mgI} / \mathrm{ml}$
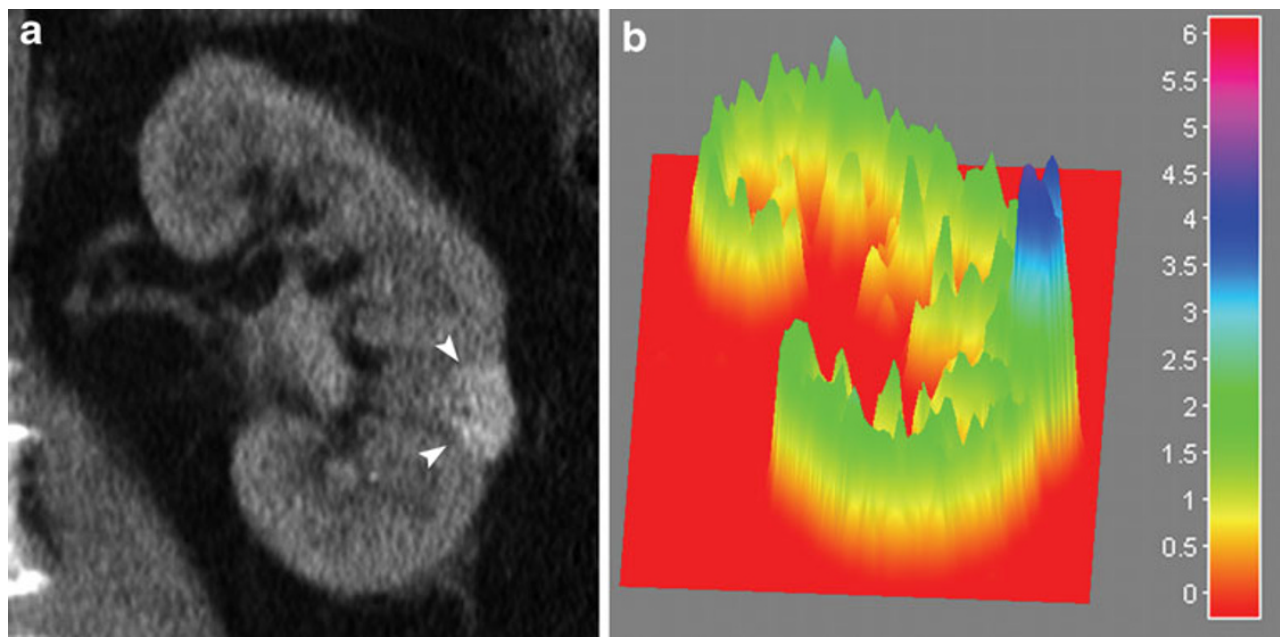

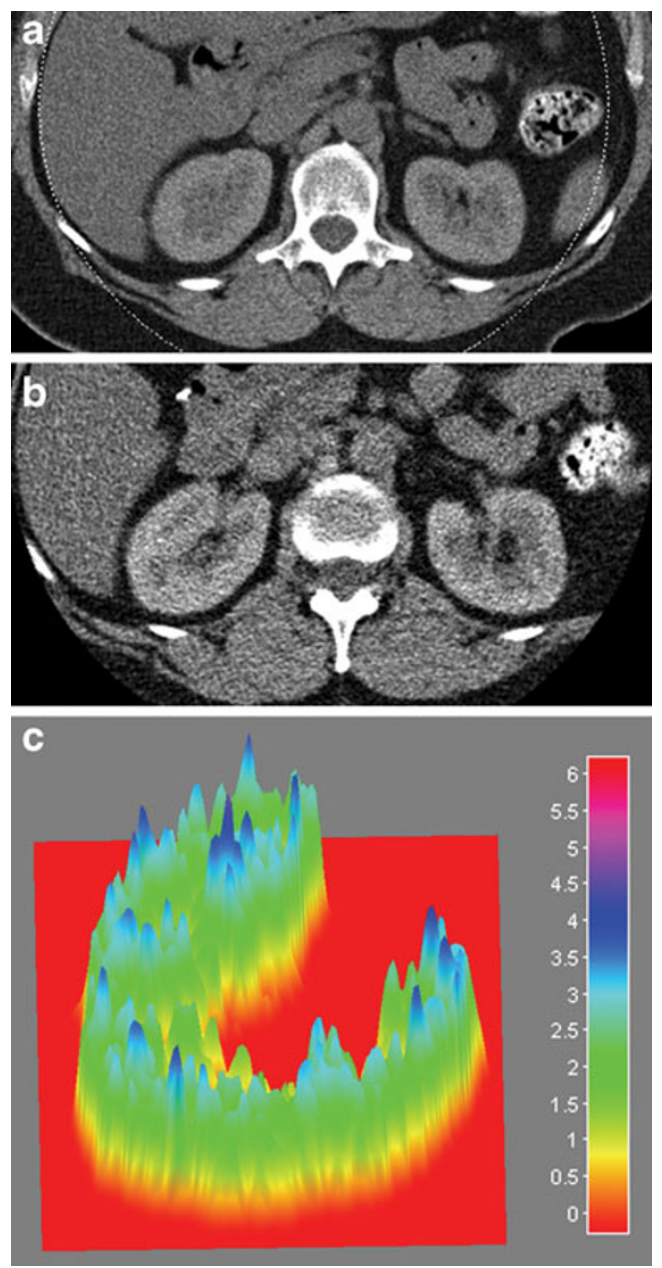

Fig. 5 Non-contrast CT images of a 56-year-old woman (patient 7) $24 \mathrm{~h}$ post coronary artery stent placement and utilising $300 \mathrm{ml} \mathrm{CM}$ and 20.5 min of fluoroscopy time. a Axial combined image shows moderately dense, bilateral nephrograms, cortical regions 71.4 and 65.1 HUs and medullary regions 44.6 and $43.1 \mathrm{HUs}$, right and left kidneys, respectively. Total iodine 444.04 and $401.17 \mathrm{mg}$, right and left kidneys respectively. b Axial CT images depicted at $80 \mathrm{kVp}$. c Axial 2D colourised graphical image of the right kidney. Vicarious excretion of $\mathrm{CM}$ is noted in the colon. The colourised scale on the right aspect of the image is in $\mathrm{mgI} / \mathrm{ml}$

contrast media. No specific etiology for these findings was offered.

Monsky et al. [12] described wedge-shaped or linear peripheral nephrograms in 24-h delayed CT scans in $23.3 \%$ $(14 / 60)$ of patients having undergone TACE and found a statistically significant $(P=0.029)$ relationship with procedure time. These authors postulated that these foci represent segmental ischemia and trapped CM in the tubular lumen. Possible etiologies include emboli from either blood or cholesterol plaques from the catheterisation procedure itself.

The well-perfused parenchyma clears the $\mathrm{CM}$, which has a normal biologic half-time of about $1.5 \mathrm{~h}$. However, in the areas with segmental ischemia, the CM does not empty, and
Table 3 Comparison of HU values and single kidney iodine (mg)

\begin{tabular}{llc}
\hline Parameters compared & Correlation coefficient & $P$ value \\
\hline RK total I vs & & \\
Cortex HU & 0.7 & $<0.0001$ \\
Medullary HU & 0.22 & 0.25 \\
LK total I vs & & \\
Cortex HU & 0.62 & 0.0005 \\
Medullary HU & 0.31 & 0.11 \\
RK vs LK & & $<0.0001$ \\
Cortex HU & 0.86 & $<0.0001$ \\
Medullary HU & 0.75 & $<0.0001$ \\
RK vs LK total iodine & 0.98 & \\
\hline
\end{tabular}

$R K$ right kidney, $L K$ left kidney

sodium and water continue to be reabsorbed from the tubular lumen and with a persistence or even an increase in $\mathrm{CM}$ concentration. This results in accentuation of the focally ischemic region in comparison with the normal parenchyma (Figs. 2a, b, 3a-c and 4a, b). Cholesterol emboli have been reported to occur in association with angiographic procedures [22, 23]. Furthermore, clots can form around the indwelling catheter. Research has shown that angiographic techniques can lead to the release of particles, presumably made up of bits of clot and fatty plaque material, into the blood. It has also been reported that cholesterol emboli are a known cause of ARF [23].

We do not have a control group of subjects having delayed non-contrast CT scans after CECT, but Jakobsen et al. [24] studied 60 healthy male volunteers by delayed CT at varying doses of iodixanol at four time points up to 5 days after injection. These investigators reported global, but no focal nephrograms.

Prior studies have indicated the observation that microemboli occur in the brain and the heart, making it highly likely that renal emboli may likely occur. Büsing et al. [6] prospectively evaluated the incidence of embolic cerebral infarction $12-48 \mathrm{~h}$ following diagnostic and interventional coronary angiography in 48 patients using diffusion weighted cerebral MR imaging finding an incidence of $15 \%(7 / 48)$, all of whom were asymptomatic. There was a statistically significant $(P=0.017)$ association with the

Table 4 Comparison of the number of focal nephrograms in each patient and total contrast medium used (mg) and total fluoroscopic time $(\mathrm{min})$

\begin{tabular}{lll}
\hline Parameters compared & Correlation coefficient & $P$ value \\
\hline $\begin{array}{l}\text { Total contrast medium vs } \\
\text { focal nephrograms }\end{array}$ & 0.28 & 0.14 \\
$\begin{array}{c}\text { Total fluoroscopic time vs } \\
\text { focal nephrograms }\end{array}$ & 0.48 & 0.0087 \\
\hline
\end{tabular}


Table 5 Comparison of Semiquantitative Global Rating Scale vs HU and iodine $(\mathrm{mg})$

\begin{tabular}{llc}
\hline Parameters compared & Correlation coefficient & $p$ value \\
\hline RK cortex HU & 0.84 & $<0.0001$ \\
RK medulla HU & 0.47 & 0.01 \\
LK cortex HU & 0.87 & $<0.0001$ \\
LK medulla HU & 0.57 & 0.002 \\
RK total I & 0.76 & $<0.0001$ \\
LK total I & 0.79 & $<0.0001$ \\
\hline
\end{tabular}

$R K$ right kidney, $L K$ left kidney

cardiac catheterisation procedure time. They postulated that cerebral emboli associated with catheterisation could be the result of loosened atherosclerotic plaque caused by catheter manipulation, thrombus formation at the catheter, air embolism or, in rare circumstance, foreign material from the catheter or guidewire. The femoral approach was used in all cases.

Lund et al. [7], using multifrequency transcranial Doppler, detected cerebral emboli in $15 \%$ of 47 patients undergoing left heart catheterisation. Neuropsychological assessment of 42 of these subjects showed that seven (16.7\%) had post catheterisation cognitive impairment.

Myocardial microinfarcts have also been identified after percutaneous coronary intervention [8-10]. Selvanayagam et al. [8] studied 50 subjects after intervention and found that $28 \%$ of them had delayed enhancement on cardiac MR images.

We excluded patients with chronic kidney disease (CKD) defined as an eGFR $<60 \mathrm{ml} / \mathrm{min}$ per $1.73 \mathrm{~m}^{2}$, subjects [25] who are known to have a much greater risk for AKI following cardiac catheterisation and intervention. This may explain our low rate of AKI as determined by changes in SCr. Further, subjects with CKD require a lesser degree of AKI (change in GFR) to manifest changes in $\mathrm{SCr}$ due to the non-linear relationship between GFR and SCr. Changes in the eGFR metric cannot be used to assess AKI, since it established only in steady state CKD subjects [15]. We have not used the term "CIN" in reporting manifestations of AKI as we agree with others that "CIN" presumes causality that may not exist $[2,4,5,26]$.

The diagnosis of AKI related to CIN is usually based on an elevation of SCr of either $\geq 44 \mu \mathrm{mol} / 1(0.5 \mathrm{mg} / \mathrm{dl})$ and/or an increase $\geq 25 \%$ over $24-72 \mathrm{~h}$ after the initial insult [16, 27]. However, it is well known that $\mathrm{SCr}$ is a poor marker of early renal dysfunction because its concentration is influenced by numerous non-renal factors [5, 28]. It is of even lesser utility in AKI because patients are not in a steady state and substantial rises are not detected until 48-72 $\mathrm{h}$ after the initial insult. Significant renal disease can exist with minimal change in $\mathrm{SCr}$ because of renal reserve and enhanced tubular secretion of creatinine [29, 30]. On the other hand, significant random $\mathrm{SCr}$ fluctuations can occur as "background noise," as pointed out by Newhouse et al. [2]. It is, thus, possible that the nephrographic patterns detected by non-contrast $\mathrm{CT}$ are more sensitive indicators of AKI and should be compared with urinary biomarkers, rather than $\mathrm{SCr}$.

The bilateral global nephrographic pattern is possibly less easy to understand. Some previous reports have equated this observation to ARF and CIN [13, 14]. Our review of that literature and the current results of this study do not necessarily document a clear association with either (Table 7). The poor sensitivity of SCr, especially in mild cases of AKI, may be an explanation for the lack of consistently proven association between persistent nephrograms and AKI.

Love et al. [14] proposed a cortical attenuation of 55$110 \mathrm{HU}$ at $24 \mathrm{~h}$ to identify patients with subclinical renal impairment and attenuations in excess of $140 \mathrm{HU}$ to be an early indicator of CIN. On the other hand, Jakobsen et al. [24] demonstrated persistence of the cortical nephrogram by sequentially timed delayed CT scans and postulated that retention of $\mathrm{CM}$ occurred in the proximal tubular cells and was greater for the nonionic dimer, iodixanol, in comparison with nonionic monomers. The HU levels we have observed and those reported by Yamazaki et al. [11] and Monsky et al. [12] are generally much higher. More than $98 \%$ of the iodixanol administered should be excreted within the first $24 \mathrm{~h}$.

It is possible that the persistent global nephrogram is not specific for AKI, but can be a manifestation of significant physiological alteration. Catheter manipulation, intralumi-

Table 6 Comparison of CM and fluoroscopic time vs renal HUs and single kidney iodine (mg)

\begin{tabular}{llc}
\hline Parameters compared & Correlation coefficient & $P$ value \\
\hline CM vs & & \\
RK cortex HU & 0.8 & $<0.0001$ \\
RK medulla HU & 0.3 & 0.12 \\
LK cortex HU & 0.72 & $<0.0001$ \\
LK medulla HU & 0.3 & 0.11 \\
RK iodine (mg) & 0.77 & $<0.0001$ \\
LK iodine (mg) & 0.74 & $<0.0001$ \\
Fluorotime vs & & \\
RK cortex HU & 0.74 & $<0.0001$ \\
RK medulla HU & 0.21 & 0.28 \\
LK cortex HU & 0.66 & $<0.0001$ \\
LK medulla HU & 0.24 & 0.21 \\
RK iodine (mg) & 0.79 & $<0.0001$ \\
LK iodine (mg) & 0.76 & $<0.0001$ \\
\hline
\end{tabular}

$R K$ right kidney, $L R K$ left kidney 
Table 7 Summary of reports on persistent global nephrograms

\begin{tabular}{|c|c|c|c|}
\hline Publication & Observations & Change in renal function & Contrast media \\
\hline $\begin{array}{l}\text { Older et al. } \\
\text { (1976) [13] }\end{array}$ & $\begin{array}{l}\text { Persistent nephrograms on plain films } 24 \mathrm{~h} \text { after angiography in } \\
17 / 90(19 \%) \text { of patients of which } 9 / 17(53 \%) \text { did have and } \\
8 / 17(47 \%) \text { did not have significant change in renal function }\end{array}$ & $\uparrow \mathrm{SCr} \geq 20 \%$ or $26.40 \mu \mathrm{mol} / 1$ & HOCM \\
\hline $\begin{array}{l}\text { Love et al. } \\
\text { (1989) [14] }\end{array}$ & $\begin{array}{l}\text { Delayed CT cortical enhancement of } 141.6 \mathrm{HU} 22-26 \mathrm{~h} \text { after } \\
\text { angiography in } 1 / 50(2 \%) \text { with any significant change in renal } \\
\text { function. Cortical enhancement of 55-110 HU classified as } \\
\text { "subclinical renal impairment" }\end{array}$ & $\begin{array}{l}\uparrow \mathrm{SCr}=150 \% \text { of baseline or } \\
88 \mu \mathrm{mol} / 1\end{array}$ & HOCM and LOCM \\
\hline $\begin{array}{l}\text { Jakobsen et al. } \\
\text { (1992) [24] }\end{array}$ & $\begin{array}{l}\text { Cortical attenuation of } 52 \pm 6 \mathrm{HU} \text { at } 8-32 \mathrm{~h} \text { in } 40 \text { healthy male } \\
\text { volunteers after CECT. No change in renal function. } \\
\text { (No focal CT nephrograms reported) }\end{array}$ & $\begin{array}{l}\uparrow \mathrm{SCr}, \mathrm{Cr} \mathrm{Cl} \text { and urinary } \\
\text { biomarkers }\end{array}$ & $\begin{array}{l}\text { LOCM, LOCM } \\
\text { ionic dimer }\end{array}$ \\
\hline $\begin{array}{l}\text { Yamazaki et al. } \\
\text { (2001) [11] }\end{array}$ & $\begin{array}{l}\text { Delayed CT cortical enhancement } 16-21 \mathrm{~h} \text { after TACE in } \\
81 / 180(45 \%) \text { and nephropathy in } 11 / 180(6 \%) \text { of treatments. } \\
\text { Minimal cortical retention }>50 \mathrm{HU} \text { and severe retention }>100 \mathrm{HU}\end{array}$ & $\uparrow \mathrm{SCr} \geq 44 \mu \mathrm{mol} / 1$ or $\geq 25 \%$ & $\begin{array}{l}\text { HOCM, LOCM, LOCM } \\
\text { ionic dimer }\end{array}$ \\
\hline $\begin{array}{l}\text { Monsky et al. } \\
\text { (2009) [12] }\end{array}$ & $\begin{array}{l}\text { CT renal nephrograms } 24 \mathrm{~h} \text { post TACE in } 14 / 60(23.3 \%) \text { treatments. } \\
\text { Global nephrograms associated with significant }(p=0.031) \\
\text { change in SCr at } 24 \mathrm{~h} \text {. (Delayed segmental nephrograms associated } \\
\text { with procedural factors) }\end{array}$ & $\begin{array}{l}\uparrow \mathrm{SCr} \text { at } 24 \mathrm{~h} \text { and } 24 \mathrm{~h} \text { from } \\
\text { baseline pre-TACE values }\end{array}$ & IOCM and LOCM \\
\hline
\end{tabular}

$\uparrow S C r$ increase in serum creatinine, $\mu \mathrm{mol} / \mathrm{l}$ micromol per liter, $\mathrm{CrCl}$ creatinine clearance, $H O C M$ high osmolar contrast media, $L O C M$ low osmolar contrast media, IOCM iso-osmolar contrast media, HU Hounsfield units, CECT contrast-enhanced CT, TACE transarterial chemoembolisation

nal aortic pressure changes due to bolus injections, temperature changes and $\mathrm{CM}$ effects on the endothelium could result in significant stimulation of a richly innervated visceral/endoluminal sympathetic nervous system leading to bilateral renal vasoconstriction [31]. This could lead to stagnation of $\mathrm{CM}$ in the tubular lumen and with a prolonged retention time. The medullary region could "flush" the distal tubular CM by persistent and possibly enhanced tubular secretion. This could be an explanation for the unexpected higher cortical than medullary attenuation. Indeed, it has been shown that the tubular secretion of endogenous creatinine increases significantly with ARF and acute glomerular diseases [29, 30, 32]. The expected typical CT nephrographic pattern following a CM i.v. bolus, for example, at $4 \mathrm{ml} / \mathrm{s}$, is an immediate corticomedullary differentiation followed by a homogenous nephrogram.

It might seem a reasonable possibility that the poorer the baseline renal function, the longer the retention of $\mathrm{CM}$. However, we did not observe a statistically significant correlation between baseline eGFR and the presence of the persistent nephrograms. These results suggest, on the other hand, the higher probability of other factors that are procedurally related as a cause.

The strengths of this study include its prospective nature, the comprehensive clinical data, especially a close monitoring of renal function, and the high rates of persistent nephrograms. The latter observations provide a foundation for a potentially rich opportunity for future investigation. The ability to detect focal nephrograms would appear useful to detect the side effects of renal emboli, providing a scoring system for guiding further innovations in cardiac catheterisation techniques. Persistent global nephrograms appear to reflect important alterations in renal physiology. Extreme alterations, especially in more vulnerable subjects with renal insufficiency could then manifest as AKI.

Weaknesses in this study include the small patient population. However, this is a pilot study and, as noted above, the findings of persistent nephrograms have been observed to be at surprisingly high rates. Only four subjects manifested significant changes in renal function as measured by their SCr. Thus, no firm conclusions can be made about any specific risk factors or relationships to CIN. The major risk factor for CIN is pre-existing renal insufficiency which was not an enrollment criterion in this study. Also, and as emphasised by Newhouse et al. [2], one must be cautious not to attribute all cases of AKI to the CM, per se, in order to avoid the post hoc, ergo propter hoc logical fallacy. Future studies will expand enrollment to include these subjects.

We did not acquire pre-cardiac catheterisation CT scans as baseline and we may have overestimated the occurrence of global nephrograms. However, we derived our subjective nephrogram ratings regarding this aspect of the study from our previous work where we did have access to this information, as reported by Monsky et al. [12]. Also, the delayed renal attenuation, we observed and defined as positive nephrograms, is similar to that reported and summarised in Table 7. It is unlikely that we have overestimated the focal nephrogram findings since no patient was enrolled if they had had CM with $72 \mathrm{~h}$ of their cardiac catheterisation procedure.

Dual-energy scan data were inadvertently lost in 11/ 29 patients. We used a methodology described in the "Electronic supplementary material" section that employed 
a novel technique of training sets derived from the data on the successfully acquired dual-energy data sets. We believe iodine quantification is a valuable approach, noting high correlation coefficients between our total renal iodine determinations and right and left kidneys, cortical HUs, global nephrograms, $\mathrm{CM}$ dose and fluoroscopic procedure times.

We estimate an additional radiation dose of approximately $3.4 \mathrm{mSv}$ for these $\mathrm{CT}$ scans, which is another negative aspect of our study. However, the incremental dose compared with the cardiac catheterisation procedure is small, the images are limited to the kidneys, and can be rapidly performed.

In conclusion, delayed CT nephrograms post cardiac catheterisation and intervention manifest a high positive occurrence of both segmental and global nephrograms. These findings correlate with procedural factors such as fluoroscopic time and total amount of contrast medium utilised. Our data, and what has been previously reported, are yet too limited to prove a relationship between the global nephrogram and CIN.

Acknowledgements This study was partly funded by grants from NIBIB (R01 EB002138) and from Siemens Healthcare (Forchheim, Germany), who manufactured the CT equipment used in this study. Research funding was also provided by Siemens Medical Systems. Statistical support was made possible by Grant Number ULI RR024146 from the National Center for Research Resources (NCRR), a component of the National Institutes of Health (NIH), and NIH Roadmap for Medical Research. Its contents are solely the responsibility of the authors and do not necessarily represent the official view of NCRR or NIH. Information on re-engineering the Clinical Research Enterprise can be obtained from http://nihroadmap.nih.gov/clinicalresearch/overview-translational.asp.

\section{References}

1. Katzberg RW, Barrett BJ (2007) Risk of iodinated contrast material-induced nephropathy with intravenous administration. Radiology 243:622-628

2. Newhouse JH, Kho D, Rao QA, Starren J (2008) Frequency of serum creatinine changes in the absence of iodinated contrast material: implications for studies of contrast nephrotoxicity. AJR Am J Roentgenol 191:376-382

3. Rudnick M, Feldman H (2008) Contrast-induced nephropathy: what are the true clinical consequences? Clin J Am Soc Nephrol 3:263-272

4. Baumgarten DA, Ellis JH (2008) Contrast-induced nephropathy: contrast material not required? AJR Am J Roentgenol 191:383386

5. Ellis JH, Cohan RH (2009) Reducing the risk of contrast-induced nephropathy: a perspective on the controversies. AJR Am J Roentgenol 192:1544-1549

6. Büsing KA, Schulte-Sasse C, Flütchers et al (2005) Cerebral infarction: incidence and risk factors after diagnostic and interven- tional cardiac catheterization - prospective evaluation at diffusionweighted MR imaging. Radiology 235:177-183

7. Lund C, Nes RB, Ugelstad TP et al (2005) Cerebral emboli during left heart catheterization may cause acute brain energy. Eur Heart J 26:1269-1275

8. Selvanayagam JB, Porto I, Channon K et al (2005) Troponin elevation after percutaneous coronary intervention directly represents the extent of irreversible myocardial injury: insights from cardiovascular magnetic resonance imaging. Circulation 111:1027-1032

9. Carlsson M, Saloner D, Martin AJ et al (2010) Heterogeneous microinfarcts caused by coronary microemboli: evaluation with multidetector CT and MR imaging in a swine model. Radiology 254:718-728

10. Gupta S, Kwong RY (2010) Multidetector CT characterization of microinfarction - is it ready for clinical use? Radiology 254:637639

11. Yamazaki H, Oi H, Matsushita M et al (2001) Renal cortical retention on delayed CT and nephropathy following transcatheter arterial chemoembolization. $\mathrm{Br} \mathrm{J}$ Radiol 74:695-700

12. Monsky WL, Pahwa A, Li C-S, Katzberg RW (2009) Clinical factors associated with dense and wedge-shaped nephrograms detected 24 hours after chemoembolization. Cardiovasc Intervent Radiol 32:1193-1201

13. Older RA, Miller J, Jackson D et al (1976) Angiographically induced renal failure and its radiographic detection. AJR Am J Roentgenol 126:1039-1025

14. Love L, Lind JA, Olson MC (1989) Persistent CT nephrogram with significance in the diagnosis of contrast nephropathy. Radiology 172:125-129

15. Levey A, Bosch JP, Lewis JB et al (1999) A more accurate method to estimate glomerular filtration rate from serum creatinine: a new prediction equation. Ann Intern Med 130:461-470

16. Thomsen HS (2007) European Society of Urogenital Radiology (ESUR) guidelines on contrast media application. Curr Opin Urol 17:70-76

17. Ishikawa I, Tateishi K, Onouchi $Z$ et al (1985) Persistent wedge-shaped contrast enhancement of the kidney. Urol Radiol 7:45-47

18. Pazmiño P, Pyatt R, Williams E et al (1983) Computed tomography in renal ischemia. J Comput Assist Tomogr 7:102105

19. Braedel HU, Schindler E, Cullen P et al (1987) Demonstration of residual contrast medium in renal parenchyma using computed tomography. J Urol 137:11-14

20. Trueba-Arguiñarena FJ, Fuertes-Alija JJ, Perez Homs M et al (1997) Unilateral tubular obstruction: an unusual complication of urographic contrast media. AJR Am J Roentgenol 169:1585-1587

21. Yamazaki H, Oi H, Matsuchita M et al (1996) Focal residual contrast media in the kidney 24 hours after angiography. Acta Radiol 37:348-351

22. Keeley EC, Grines CL (1998) Scraping of aortic debris by coronary guiding catheters. A prospective evaluation in 1,000 cases. J Am Coll Cardiol 32:1861-1865

23. Vidt DG (1997) Cholesterol emboli, a common cause of renal failure. Annu Rev Med 48:375-385

24. Jakobsen JA, Lundby B, Kristoffersen DT et al (1992) Evaluation of renal function with delayed $\mathrm{CT}$ after injection of nonionic monomeric and dimeric contrast media in healthy volunteers. Radiology 182:419-424

25. K/DOQI clinical practice guidelines for chronic kidney disease: evolution, classification, and stratification (2002) Am J Kidney Dis 39(Suppl):S1-S266 
26. Katzberg RW, Newhouse JH (2010) Intravenous contrast mediuminduced nephrotoxicity: is the medical risk really as great as we've come to believe? Radiology 256:21-28

27. Mehta RL, Chertow GM (2003) Acute renal failure definitions and classifications: a time for change? J Am Soc Nephrol 14:2178-1287

28. Bjornsson TD (1979) Use of serum creatinine concentrations to determine renal function. Clin Pharmacokinet 4:200-222

29. Bosch JP (1995) Renal reserve: a functional view of glomerular filtration rate. Semin Nephrol 15:381-385
30. Herrera J, Rodriquezz-Iturbe (1988) Stimulation of tubular secretion of creatinine in health and in conditions associated with reduced nephron mass. Evidence for a tubular functional reserve. Nephrol Dial Transplant 13:623-629

31. Dibona GF, Kopp UC (1997) Neural control of renal function. Physiol Rev 77:75-97

32. Shemesh O, Golbetz H, Kriss JP et al (1985) Limitations of creatinine as a filtration marker in glomerulopathic patients. Kidney Int 28:830-838 